\title{
Effects of Freeze-Thaw Cycles on Soil Properties and Carbon Distribution in Saline-alkaline Soil of Wetland
}

\author{
Qian Liu, ${ }^{1}$ Jie Tang, ${ }^{2 *}$ Cheng Shuai He, ${ }^{1}$ Yang Long, ${ }^{1}$ and Chia-Chun $\mathrm{Wu}^{3 * *}$ \\ ${ }^{1}$ College of Landscape Architecture, Changchun University, Changchun 130012, China \\ ${ }^{2}$ College of New Energy and Environment, Jilin University, Changchun 130012, China \\ ${ }^{3}$ Department of Industrial Engineering and Management, National Quemoy University, Kinmen 892, Taiwan
}

(Received May 12, 2020; accepted December 2, 2020)

Keywords: freeze-thaw, saline-alkali wetland, active organic carbon, physical and chemical properties

The effects of freeze-thaw cycles on the physicochemical properties and carbon components in saline-alkali wetland soil were investigated. The results showed that the water content and bulk density of the soil increased, while soil $\mathrm{pH}$ decreased with increasing number of freezethaw cycles. Organic carbon content in the soil was not significantly affected by the freezethaw cycles. In contrast, water-soluble organic carbon (WSOC), microbial biomass carbon $(\mathrm{MBC})$, and readily oxidized organic carbon (ROOC) contents were significantly affected by the cycles. The various carbon contents showed a common tendency to increase first and then decrease steadily with repeated cycles; the change in carbon content was stable after several freeze-thaw cycles. The correlation between soil organic carbon and active carbon components was significant within the temperature range of $-5-5{ }^{\circ} \mathrm{C}$. However, the correlation became significant only after the first cycle. Repeated cycles and low freeze-thaw temperatures seem to affect the redistribution of carbon components in the soil. The results of this study provide basic data to support the accurate estimation of the effects of freeze-thaw cycles on soil carbon pools in saline-alkali wetlands and to reveal the responses of soil physical and chemical properties and active carbon components to the cumulative effects of freeze-thaw cycles.

\section{Introduction}

Global warming is becoming more serious worldwide, affecting the natural environment more than ever. It also affects the freeze-thaw process in the soil of the temperate zone. The process considerably changes the soil properties. It is estimated that about $70 \%$ of the world's land area and more than $80 \%$ of the soil in China are affected by the freeze-thaw process even in the permafrost area. ${ }^{(1)}$ Various studies have proven that the freeze-thaw process is one of the important factors that affect terrestrial ecosystem cycles. It also alters the physical, chemical, and biological properties of soil such as water content, $\mathrm{pH}$, and conductivity, as the repeated process eventually alters the soil nutrient and carbon cycles. ${ }^{(2-4)}$ Several researchers have studied the effects of the freeze-thaw process on the physical and chemical properties of soil, specifically, the organic carbon contents in alpine meadows, farmland, and forest ecosystems. ${ }^{(5-7)}$

\footnotetext{
*Corresponding author: e-mail: tangjie0724@126.com

** Corresponding author: e-mail: ccwu0918@nqu.edu.tw

https://doi.org/10.18494/SAM.2021.3012
} 
The change of the soil organic carbon pool during repeated freeze-thaw processes is well known. The physical and chemical properties of soil are closely related to the change in soil organic carbon content, which is an important indicator of changes in the organic carbon pool. ${ }^{(8)}$ The results of previous studies suggest that freeze-thaw events also affect microbial metabolic activities and greenhouse gas emissions related to these activities in soils. However, studies on the effects of freeze-thaw processes on the active components of soil organic carbon are few, even though the effects of different freeze-thaw events on the carbon cycle are believed to change the active organic carbon components. ${ }^{(9-11)}$ Along with the lack of studies on the relationship between the freeze-thaw process and the active carbon components, it is worth noting that there is also a lack of studies on saline-alkali soil, especially in wetlands. Moreover, an effective real-time monitoring of the freeze-thaw temperature has not been carried out. Therefore, we aim to monitor the freeze-thaw cycle using improved temperature sensors in order to obtain more accurate data.

Thus, the objective of this study is to elucidate how the freeze-thaw cycles change the carbon components in the soil of saline-wetland, focusing particularly on saline-alkali wetland soil. The results from the experiments are expected to lead to a scientific explanation of the effects of the freeze-thaw process on the physical and chemical properties and the carbon cycle of soil. We expect to obtain basic data that can be used to predict and estimate how global warming affects the carbon stock of saline-wetland through freeze-thaw events.

\section{Materials and Methods}

\subsection{Study area}

The study area is located in the Chagan Lake Nature Reserve within Songnen Plain (Fig. 1). The area of the natural reserve is $50684 \mathrm{~km}^{2}$ with a peripheral protection zone of $14666 \mathrm{~km}^{2}$. The total area of Songnen Plain is about $578000 \mathrm{~km}^{2}$, and the plain is one of the largest areas with saline-alkaline soil in the world. Because of the effects of global warming and the increase
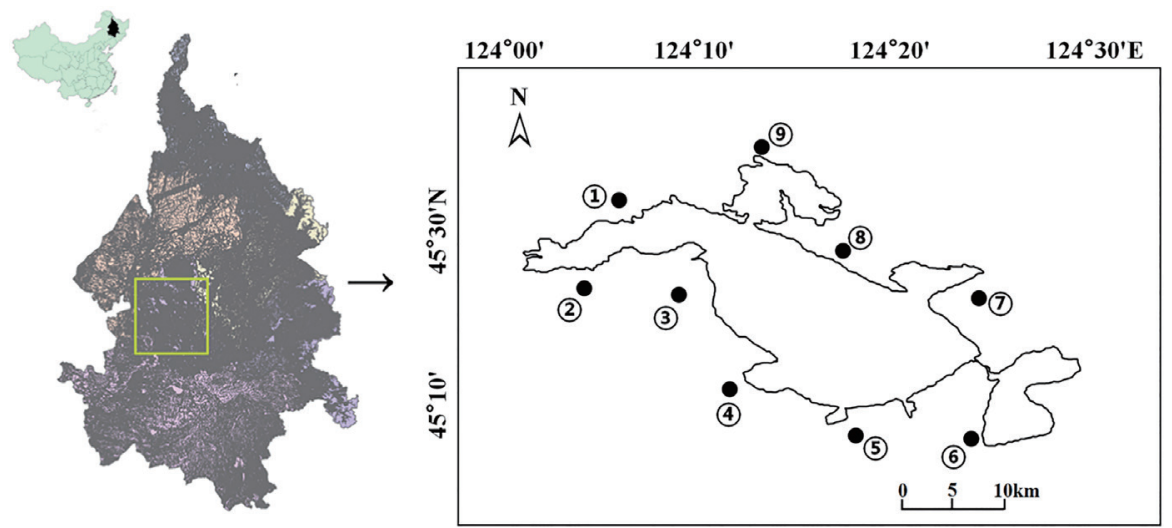

Fig. 1. (Color online) Study area around Chagan Lake. Chagan Lake is one of the lakes located in the area of Songnen Plain marked by the yellow box. Numbers in circles show sampling sites. 
in the number of human activities, the salinization of the wetland has intensified. More than two-thirds of the wetland is affected by secondary salinization. The area has a temperate continental monsoon climate characterized by a dry and windy spring, a hot and humid summer with heavy rainfall, a large daily temperature difference in autumn, and a long and cold winter with little snow. The average annual precipitation is $415.4 \mathrm{~mm}$, while the average annual evaporation is $964 \mathrm{~mm}$. The annual average temperature is $4.5^{\circ} \mathrm{C}$, the annual average wind speed is around $3.9 \mathrm{~m} \cdot \mathrm{s}^{-1}$, and the maximum frozen depth is $204 \mathrm{~cm} .{ }^{(12)}$

\subsection{Soil sample collection}

(1) Determine the research sampling point

The sample collection location was established on the basis of remote sensing data, GPS data, and the soil type map. The sampling points were evenly distributed and covered the entire study area.

(2) Soil sample collection

The S-shape sampling method was adopted to uniformly collect soil of the same type at nine sampling points from five different depth ranges of $0-10,10-20,20-30,30-40$, and 40-50 cm. The samples of the same soil layer at each sampling point were mixed. Plant residues and roots from the soil were removed and placed in plastic bags (fresh soil was kept at $4{ }^{\circ} \mathrm{C}$ and dry soil was kept at room temperature) until measurement.

(3) Laboratory simulation freeze-thaw test

The tests were carried out indoors and test soil samples were divided into two groups. Using a temperature sensor, we determined the freeze-thaw temperature, monitoring all events in real time (Fig. 2). Freeze-thaw cycles were performed at $-5-5$ and $-25-5{ }^{\circ} \mathrm{C}$ with two gradients, i.e., the sample was frozen at -5 or $-25^{\circ} \mathrm{C}$ and held for $24 \mathrm{~h}$, and then thawed at $5{ }^{\circ} \mathrm{C}$ and held for

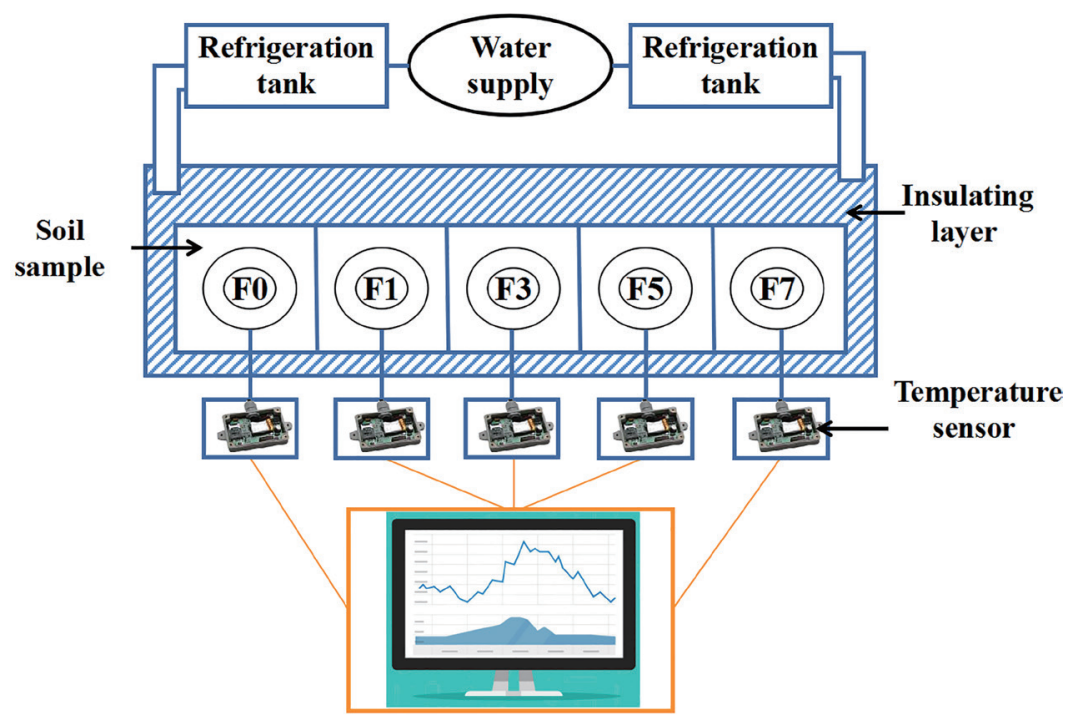

Fig. 2. (Color online) Temperature sensing system. 
$24 \mathrm{~h}$; this is one freeze-thaw cycle. Samples were subjected to $0,1,3,5$ or 7 freeze-thaw cycles (referred to as FT0, FT1, FT3, FT5, and FT7, respectively), and each soil sample underwent three repeated tests for accuracy. The experimental process is shown in Fig. 3.

\subsection{Analysis of chemical and physical properties and carbon contents}

Soil $\mathrm{pH}$ was analyzed with a $\mathrm{pH}$ meter, bulk density was determined by the ring-knife method, and water content was measured by standard methods in accordance with the drying method. We analyzed soil organic carbon (SOC) by the $\mathrm{H}_{2} \mathrm{SO}_{4}-\mathrm{K}_{2} \mathrm{CrO}_{7}$ external heating method and readily oxidized organic carbon (ROOC) by the $333 \mathrm{mmol} \cdot \mathrm{L}^{-1} \mathrm{KMnO}_{4}$ oxidationspectrophotometer method. Water-soluble organic carbon (WSOC) was analyzed by the following method. We air-dried $10 \mathrm{~g}$ of soil samples and put them in plastic centrifugal tubes with $50 \mathrm{~mL}$ of distilled water. The tubes were shaken for $30 \mathrm{~min}$ and then centrifuged at $4500 \mathrm{rpm}$ for $20 \mathrm{~min}$. Supernatants in the tubes were filtered with membrane filters of $0.45 \mu \mathrm{m}$ pore size and then analyzed by $\mathrm{H}_{2} \mathrm{SO}_{4}-\mathrm{K}_{2} \mathrm{CrO}_{7}$ external heating. Microbial biomass carbon (MBC) in the samples was treated by chloroform fumigation by the $0.5 \mathrm{~mol} \cdot \mathrm{L}^{-1} \mathrm{~K}_{2} \mathrm{SO}_{4}$ leaching-water bath method, then analyzed by the same method as for WSOC.

\subsection{Data analysis}

SPSS 24.0 and Office Excel 2003 were used for statistical analysis and data mapping including linear regression analysis and Pearson correlation coefficients.

\section{Results and Analysis}

\subsection{Physical and chemical properties of soil subjected to freeze-thaw cycles}

\section{Water content}

Soil freeze-thaw affects the distribution and volume changes of water in the soil layer. ${ }^{(12,13)}$ As can be seen from Fig. 4, repeated freeze-thaw cycles generally increase the water content of soil. The samples before applying the freeze-thaw cycle had water contents in the range of $40-45.5 \%$, which increased with depth. The samples after the freeze-thaw cycles had water

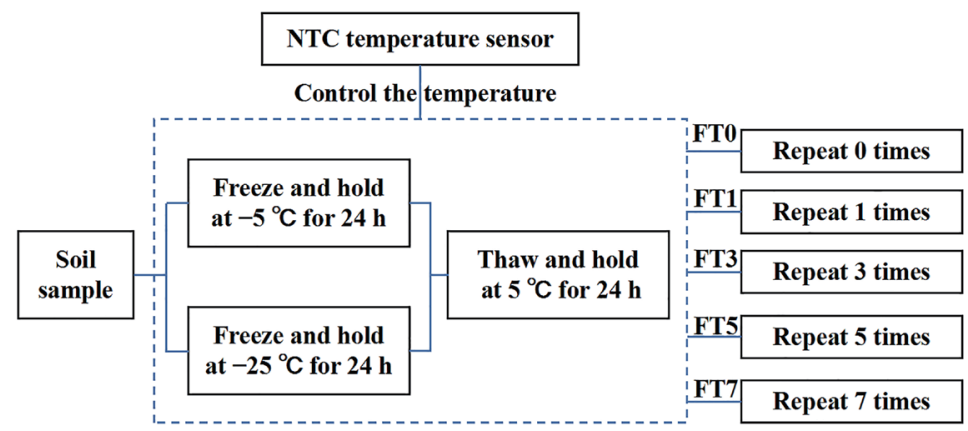

Fig. 3. (Color online) Freeze-thaw cycle in experiments. 


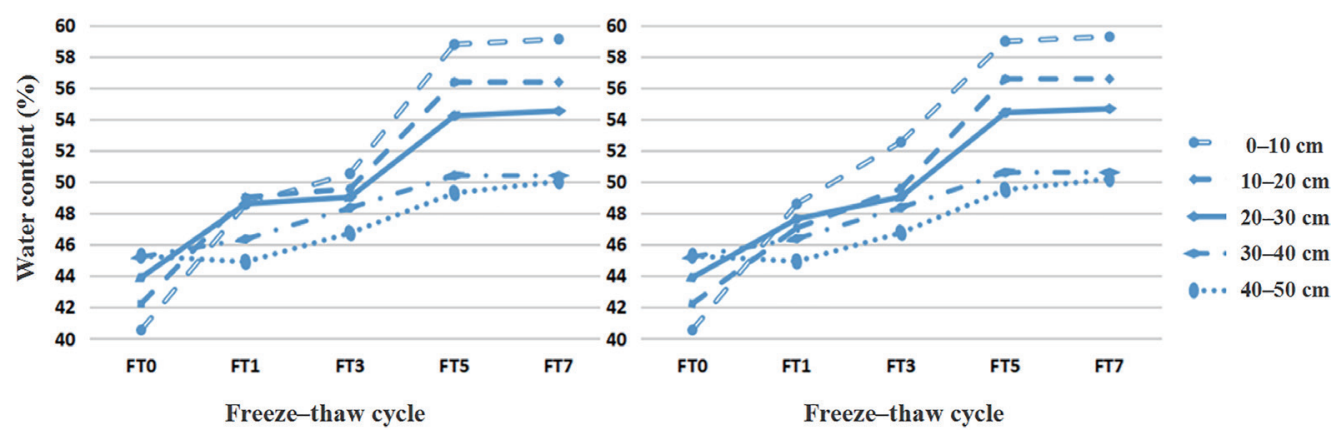

Fig. 4. (Color online) Effects of freeze-thaw cycles on soil water content. (a) Cycle temperatures of $-5-5{ }^{\circ} \mathrm{C}$. (b) Cycle temperatures of $-25-5{ }^{\circ} \mathrm{C}$.

Table 1

Changes in water content in soil samples with depth and number of freeze-thaw cycles.

\begin{tabular}{lcccccc}
\hline \multirow{2}{*}{ Temperature } & $\begin{array}{c}\text { Depth } \\
(\mathrm{cm})\end{array}$ & $\begin{array}{c}\text { FT0 } \\
\text { Water content }(\%)\end{array}$ & \multicolumn{3}{c}{ Increase in water content from FT0 (\%) } \\
\hline \multirow{3}{*}{$-5-5{ }^{\circ} \mathrm{C}$} & $0-10$ & 40.53 & 20 & 25 & 45 & 46 \\
& $10-20$ & 42.21 & 16 & 17 & 34 & 34 \\
& $20-30$ & 43.88 & 11 & 12 & 24 & 24 \\
& $30-40$ & 45.21 & 2 & 7 & 11 & 12 \\
& $40-50$ & 45.27 & -1 & 3 & 9 & 10 \\
$-25-5{ }^{\circ} \mathrm{C}$ & $0-10$ & 40.53 & 20 & 25 & 45 & 46 \\
& $10-20$ & 42.21 & 16 & 17 & 34 & 34 \\
& $20-30$ & 43.88 & 11 & 12 & 24 & 25 \\
& $30-40$ & 45.21 & 3 & 7 & 12 & 12 \\
& $40-50$ & 45.27 & -1 & 3 & 9 & 11 \\
\hline
\end{tabular}

contents in the range of $45.2-49.5 \%$, which decreased with depth. After freeze-thaw cycles (FT1 to FT7) with temperatures in the range of $-5-5{ }^{\circ} \mathrm{C}$, the water content increased from 16 to $34 \%(10-20 \mathrm{~cm})$, from 11 to $24 \%(20-30 \mathrm{~cm})$, from 2 to $12 \%(30-40 \mathrm{~cm})$, and from -1 to $10 \%$. The tendency of the water content to increase with depth and the number of cycles was almost the same for the temperature range of $-5-25^{\circ} \mathrm{C}$. This result indicated that the repeatedly frozen and thawed soil in the study area loses aggregate stability, and that deeper soil seems to be more packed and loses less stability. The repetition of freeze-thaw cycles significantly affects soil stability (Table 1).

\section{Bulk density}

Freeze-thaw cycles cause the volume of soil to expand and shrink, resulting in a change in soil bulk density. ${ }^{(14)}$ Before applying the freeze-thaw cycle, the bulk densities of the soil at depths of $0-10,10-20$, and $20-30 \mathrm{~cm}$ were very similar: $0.47,0.46$, and $0.46 \mathrm{~g} \cdot \mathrm{cm}^{-3}$, respectively. However, at greater depths of $30-40$ and $40-50 \mathrm{~cm}$, the bulk densities were lower at 0.38 and $0.33 \mathrm{~g} \cdot \mathrm{cm}^{-3}$, respectively. The bulk density of the soil at the depth of $0-30 \mathrm{~cm}$ negligibly changed with the number of freeze-thaw cycles, but that at the depth of 30-50 cm significant increased (Table 2, Fig. 5). The freeze-thaw cycles affected the aggregation of soil particles, which is dependent on the composition of the soil. It is clear that the soil at greater 
Table 2

Changes in bulk density of soil samples with depth and number of freeze-thaw cycles.

\begin{tabular}{lcccccc}
\hline \multirow{2}{*}{ Temperature } & Depth & FT0 & FT1 & FT3 & FT5 & FT7 \\
\cline { 3 - 6 } & $(\mathrm{cm})$ & Bulk density $\left(\mathrm{g} \cdot \mathrm{cm}^{-3}\right)$ & \multicolumn{3}{c}{ Increase in bulk density from FT0 (\%) } \\
\hline \multirow{3}{*}{$-5-5{ }^{\circ} \mathrm{C}$} & $0-10$ & 0.462 & 0.6 & 0.6 & 0.9 & 0.6 \\
& $10-20$ & 0.463 & 0.2 & 0.9 & 0.4 & 0.4 \\
& $20-30$ & 0.462 & 0.4 & 0.2 & 0.4 & 0.2 \\
& $30-40$ & 0.38 & 5.3 & 16.6 & 17.4 & 17.1 \\
& $40-50$ & 0.33 & 9.1 & 15.5 & 14.8 & 15.8 \\
$-25-5{ }^{\circ} \mathrm{C}$ & $0-10$ & 0.462 & 2.8 & 5.0 & 4.1 & 3.9 \\
& $10-20$ & 0.463 & 2.4 & 5.2 & 3.7 & 3.7 \\
& $20-30$ & 0.462 & 2.6 & 4.5 & 3.7 & 3.5 \\
& $30-40$ & 0.38 & 7.9 & 21.8 & 21.3 & 21.1 \\
& $40-50$ & 0.33 & 12.1 & 21.5 & 19.4 & 20.3 \\
\hline
\end{tabular}

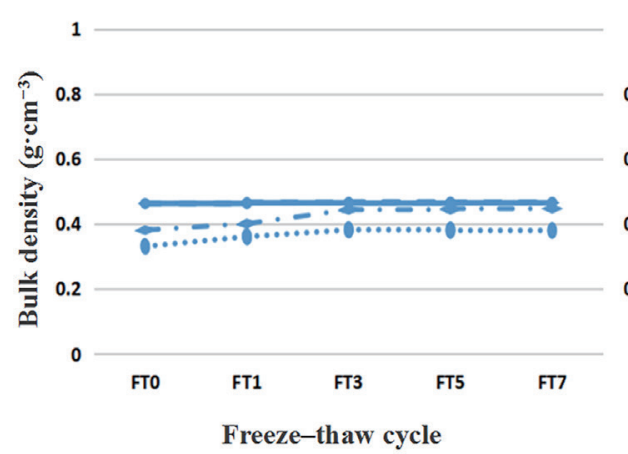

(a)

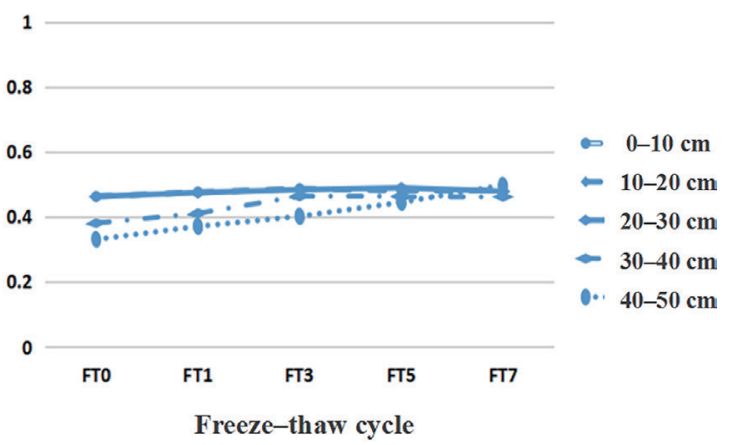

(b)

Fig. 5. (Color online) Effects of freeze-thaw cycles on soil bulk density. (a) Cycle temperatures of $-5-5{ }^{\circ} \mathrm{C}$. (b) Cycle temperatures of $-25-5^{\circ} \mathrm{C}$.

depths in the study area was much more affected by the freeze-thaw cycles probably because of the specific composition of the soil.

When we compared the water contents and bulk densities of the soil samples, we found that the two properties had a slightly negative relationship before the freeze-thaw cycle. However, the water content increased with the bulk density (Fig. 6). Generally, increasing the water content lowers the bulk density as the bulk density is defined as the mass of dried soil divided by the total volume of soil. This is true for the soil not subjected to the freeze-thaw cycle. Repeated freeze-thaw cycles increased the bulk density as well as the water content, but decreased the total volume of soil at greater depths in the study area. This prompts further research on mineralogy and sedimentology.

pH

Li et al. found that the freeze-thaw cycle not only affects the physical structure of soil, but also the soil $\mathrm{pH} .{ }^{(15)}$ After three freeze-thaw cycles, the soil $\mathrm{pH}$ showed a decreasing trend, and the $\mathrm{pH}$ range of five to seven freeze-thaw cycles was not obvious. The $\mathrm{pH}$ of the soil samples ranged from 7.0 to 7.5 and decreased with increasing depth. Even with repeated cycles, the tendency with depth was the same. The temperature range of the cycles had no significant effect on the soil pH (Table 3, Fig. 7). 


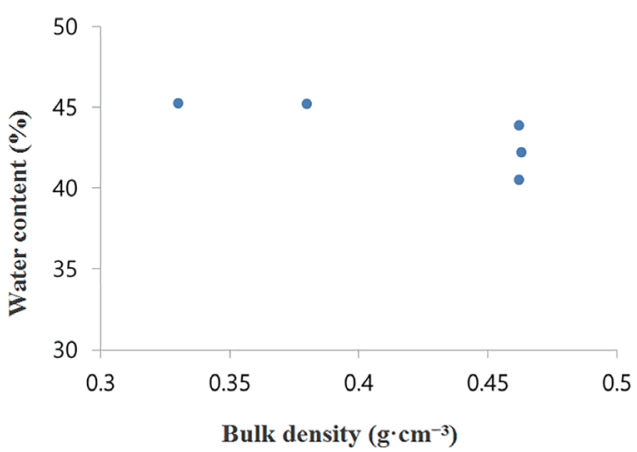

(a)

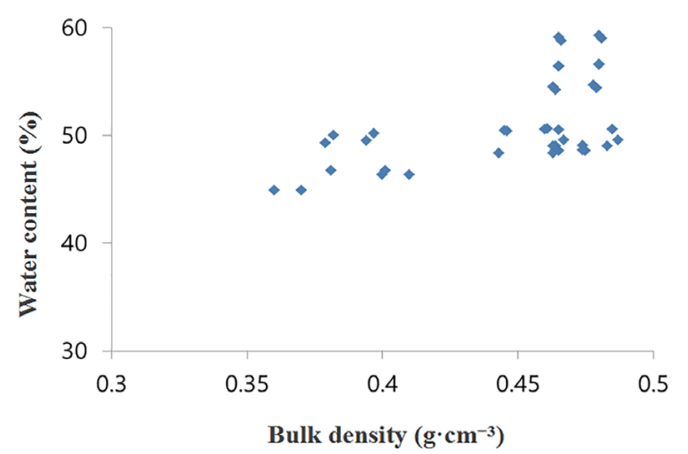

(b)

Fig. 6. (Color online) Relationship of bulk density with water content in the soil. (a) Bulk density and water content in soil samples without freeze-thaw cycle. (b) Bulk density and water content in soil samples with freezethaw cycle.

Table 3

Changes in $\mathrm{pH}$ of soil samples with depth and number of freeze-thaw cycles.

\begin{tabular}{|c|c|c|c|c|c|c|}
\hline \multirow{2}{*}{ Temperature } & \multirow{2}{*}{$\begin{array}{c}\text { Depth } \\
\text { (cm) }\end{array}$} & \multirow{2}{*}{$\begin{array}{c}\text { FT0 } \\
\text { pH }\end{array}$} & FT1 & FT3 & FT5 & FT7 \\
\hline & & & \multicolumn{4}{|c|}{ Increase in pH from FT0 (\%) } \\
\hline \multirow{5}{*}{$-5-5^{\circ} \mathrm{C}$} & $0-10$ & 7.52 & -0.4 & -2.5 & -3.1 & -3.5 \\
\hline & $10-20$ & 7.11 & 0.1 & -0.6 & -0.8 & -1.1 \\
\hline & $20-30$ & 7.09 & -0.1 & -0.8 & -1.3 & -1.6 \\
\hline & $30-40$ & 7.05 & 0.0 & -0.4 & -1.4 & -2.3 \\
\hline & $40-50$ & 7.04 & -0.1 & -0.7 & -2.3 & -2.8 \\
\hline \multirow{5}{*}{$-25-5^{\circ} \mathrm{C}$} & $0-10$ & 7.52 & -0.3 & -2.3 & -2.8 & -3.2 \\
\hline & $10-20$ & 7.11 & 1.7 & 1.1 & -0.6 & -0.8 \\
\hline & $20-30$ & 7.09 & 0.0 & -0.6 & -0.7 & -1.3 \\
\hline & $30-40$ & 7.05 & 0.1 & -0.1 & -1.1 & -2.0 \\
\hline & $40-50$ & 7.04 & 0.0 & -0.4 & -2.0 & -2.6 \\
\hline
\end{tabular}

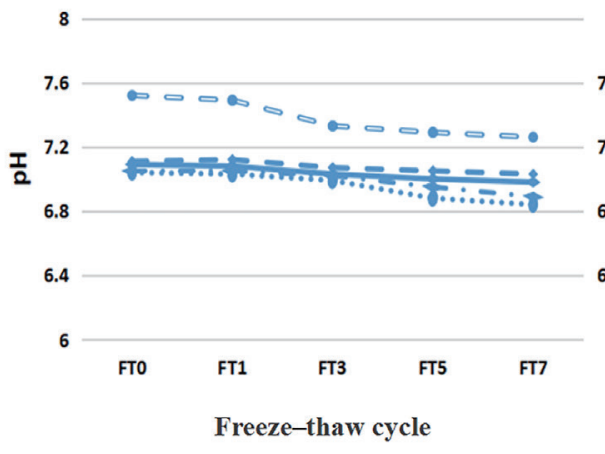

(a)

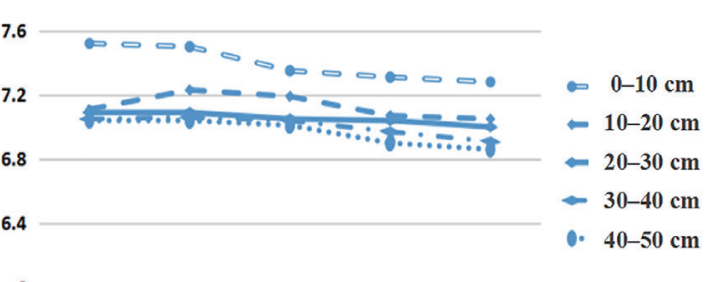

Freeze-thaw cycle

(b)

Fig. 7. (Color online) Effect of freeze-thaw cycles on soil pH. (a) Cycle temperatures of $-5-5{ }^{\circ} \mathrm{C}$. (b) Cycle temperatures of $-25-5{ }^{\circ} \mathrm{C}$

\subsection{SOC content}

The SOC content without the cycle was $16.28 \mathrm{~g} \cdot \mathrm{kg}^{-1}$ in the surface layer and gradually decreased to $14.61,13.71,13.83$, and $12.78 \mathrm{~g} \cdot \mathrm{kg}^{-1}$ in the depth ranges of $10-20,20-30,30-40$, and $40-50 \mathrm{~cm}$, respectively (Table 4, Fig. 8). The freeze-thaw cycles with the temperature 
Table 4

Changes in SOC content in soil samples with depth and number of freeze-thaw cycles.

\begin{tabular}{|c|c|c|c|c|c|c|}
\hline \multirow{2}{*}{ Temperature } & \multirow{2}{*}{$\begin{array}{l}\text { Depth } \\
\text { (cm) }\end{array}$} & \multirow{2}{*}{$\begin{array}{c}\text { FT0 } \\
\text { SOC }\left(\mathrm{g} \cdot \mathrm{kg}^{-1}\right)\end{array}$} & FT1 & FT3 & FT5 & FT7 \\
\hline & & & \multicolumn{4}{|c|}{ Changes in SOC from FT0 (\%) } \\
\hline \multirow{5}{*}{$-5-5^{\circ} \mathrm{C}$} & $0-10$ & 16.28 & 0.3 & -2.8 & -5.0 & -4.0 \\
\hline & $10-20$ & 14.61 & -0.8 & 0.0 & -3.4 & -1.8 \\
\hline & $20-30$ & 13.71 & 2.9 & -5.2 & 1.0 & 0.3 \\
\hline & $30-40$ & 13.83 & -1.7 & -4.1 & -2.2 & -0.5 \\
\hline & $40-50$ & 12.78 & -3.1 & -3.8 & -2.2 & -2.8 \\
\hline \multirow{5}{*}{$-25-5^{\circ} \mathrm{C}$} & $0-10$ & 16.28 & 5.7 & -1.9 & -6.6 & -3.6 \\
\hline & $10-20$ & 14.61 & 3.4 & -0.1 & -2.6 & -3.3 \\
\hline & $20-30$ & 13.71 & 4.5 & -0.5 & -2.6 & -2.0 \\
\hline & $30-40$ & 13.83 & 2.4 & -10.0 & -3.0 & 2.6 \\
\hline & $40-50$ & 12.78 & 1.7 & 0.2 & -0.5 & -2.0 \\
\hline
\end{tabular}

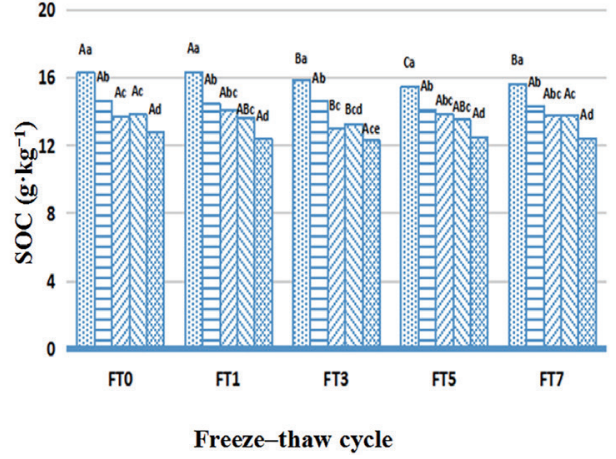

(a)

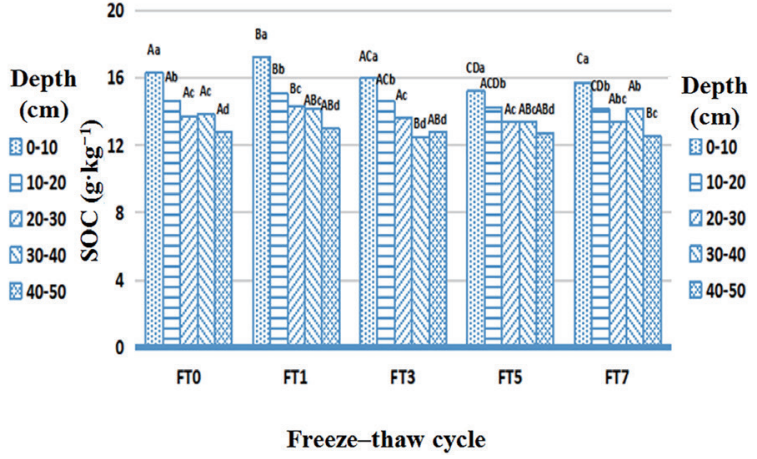

(b)

Fig. 8. (Color online) Effect of freeze-thaw cycles on SOC content. (a) Cycle temperatures of $-5-5{ }^{\circ} \mathrm{C}$. (b) Cycle temperatures of $-25-5^{\circ} \mathrm{C}$.

range of $-5-5{ }^{\circ} \mathrm{C}$ generally caused a decrease in SOC content, without any specific tendency. However, with the temperature range of $-25-5{ }^{\circ} \mathrm{C}$, the SOC contents in soil samples from all depths increased after the first cycle, then decreased. There was no specific tendency of the decrease in SOC content after three cycles. This implies that the number of cycles had little effect on the SOC content change, while the larger difference in temperature caused an increase in SCO content in the soil samples.

\subsection{ROOC content}

ROOC is a sensitive indicator of the dynamic change of a soil carbon pool. The freeze-thaw cycles have a significant impact on the change in soil ROOC content. ${ }^{(16)}$ Before the freeze-thaw cycles, the contents of ROOC were $11.13,8.96,7.42,6.70$, and $5.63 \mathrm{~g} \cdot \mathrm{kg}^{-1}$ in the depth ranges of 10-20, 20-30, 30-40, and 40-50 cm, respectively. As seen from Table 5 and Fig. 9, the ROOC content in the soil generally increased after the first cycle, decreased after three cycles, and then slightly increased again with more freeze-thaw cycles. With cycle temperatures of $-5-5$ ${ }^{\circ} \mathrm{C}$, the ROOC contents of the soils in the depth ranges of $0-10,10-20,20-30,30-40$, and 
Table 5

Changes in ROOC content in soil samples with depth and number of freeze-thaw cycles.

\begin{tabular}{lcccccr}
\hline Temperature & $\begin{array}{c}\text { Depth } \\
(\mathrm{cm})\end{array}$ & $\begin{array}{c}\text { FT0 } \\
\text { ROOC }\left(\mathrm{g} \cdot \mathrm{kg}^{-1}\right)\end{array}$ & FT1 & $\begin{array}{c}\text { FT3 } \\
\text { Changes in ROOC from FT0 }\end{array}$ & $\begin{array}{c}\text { FT5 } \\
\text { (rom7 }\end{array}$ \\
\hline \multirow{3}{*}{$-5-5{ }^{\circ} \mathrm{C}$} & $0-10$ & 11.13 & 15.8 & -4.3 & 2.1 & 4.8 \\
& $10-20$ & 8.96 & 28.4 & -9.4 & 6.3 & 11.6 \\
& $20-30$ & 7.42 & 41.3 & 7.7 & 14.8 & 28.8 \\
& $30-40$ & 6.70 & 53.6 & -2.8 & 6.5 & 27.7 \\
$-25-5{ }^{\circ} \mathrm{C}$ & $40-50$ & 5.63 & 45.6 & -2.5 & 1.2 & 16.0 \\
& $0-10$ & 11.13 & 22.3 & -3.7 & -0.8 & 6.3 \\
& $10-20$ & 8.96 & 28.7 & -7.0 & 7.8 & 7.3 \\
& $20-30$ & 7.42 & 35.2 & -3.8 & -1.3 & 16.2 \\
& $30-40$ & 6.70 & 55.0 & -0.8 & 9.9 & 25.9 \\
\hline
\end{tabular}

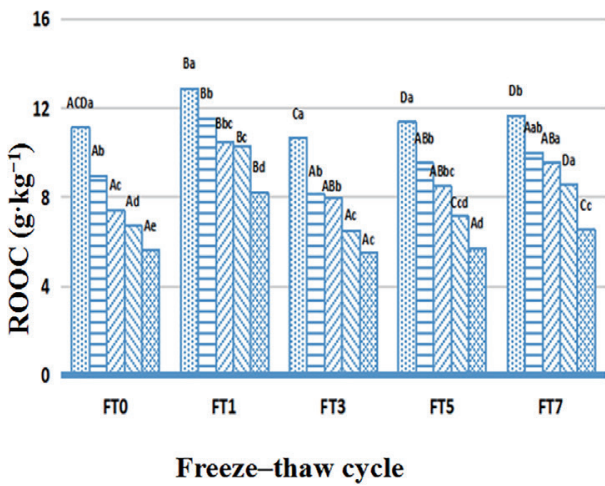

(a)

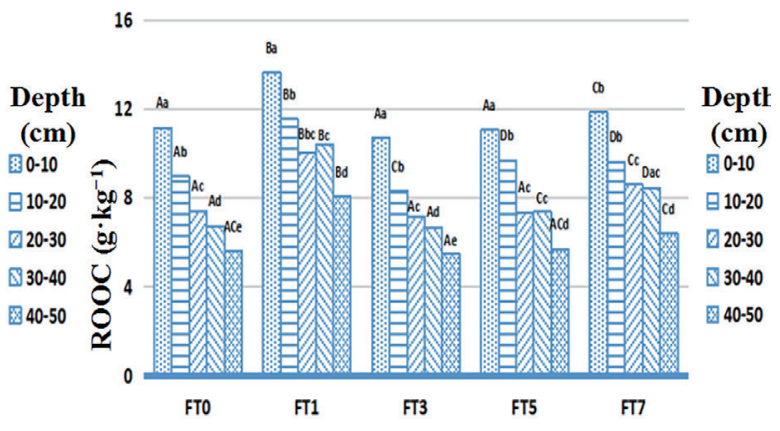

Freeze-thaw cycle

(b)

Fig. 9. (Color online) Effect of freeze-thaw cycles on ROOC content. (a) Cycle temperatures of $-5-5{ }^{\circ} \mathrm{C}$. (b) Cycle temperatures of $-25-5^{\circ} \mathrm{C}$.

$40-50 \mathrm{~cm}$ increased by $15.8,28.4,41.3,53.6$, and $45.6 \%$ after the first cycle, respectively. With cycle temperatures of $-25-5{ }^{\circ} \mathrm{C}$, the increases in ROOC content were 22.3, 28.7, 35.2, 55.0, and $42.9 \%$, respectively. In general, there was no significant difference in ROOC content after the fifth cycle.

\subsection{MBC content}

Microorganisms in soil are directly related to MBC, which is the most active carbon in soil. The MBC content is often used as an indicator of changes in the carbon cycle in soil. ${ }^{(17)}$ Without freeze-thaw cycles, the contents of MBC were $0.91,0.79,0.65,0.62$, and $0.39 \mathrm{~g} \cdot \mathrm{kg}^{-1}$ in the depth ranges of 10-20, 20-30, 30-40, and 40-50 cm, respectively. Table 6 and Fig. 10 show that the MBC contents in soil increased by 7.4-42.4 and 8.8-66.1\% after three freeze-thaw cycles with the temperature ranges of $-5-5$ and $-25-5{ }^{\circ} \mathrm{C}$, respectively. The change in $\mathrm{MBC}$ content in the soil was larger when the temperature range was $-25-5{ }^{\circ} \mathrm{C}$ than when the temperature range was $-5-5{ }^{\circ} \mathrm{C}$. This result confirmed that the microbial activity first enhanced after a few freezethaw cycles but then decreased abruptly. It seems that the microorganisms in the soil showed 
Table 6

Changes in MBC content in soil samples with depth and number of freeze-thaw cycles.

\begin{tabular}{lccrrrr}
\hline \multirow{2}{*}{ Temperature } & Depth & FT0 & FT1 & FT3 & FT5 & FT7 \\
\cline { 3 - 7 } & $(\mathrm{cm})$ & MBC $\left(\mathrm{g} \cdot \mathrm{kg}^{-1}\right)$ & & Changes in MBC from FT0 $(\%)$ & \\
\hline \multirow{3}{*}{$5-5{ }^{\circ} \mathrm{C}$} & $0-10$ & 0.91 & 7.4 & 16.5 & -4.0 & -21.0 \\
& $10-20$ & 0.79 & 5.9 & 17.3 & -7.2 & -17.7 \\
& $20-30$ & 0.65 & 10.7 & 24.5 & -5.6 & -13.3 \\
& $30-40$ & 0.62 & 13.9 & 25.1 & -12.3 & -28.3 \\
& $40-50$ & 0.39 & 17.8 & 42.4 & 5.1 & -21.2 \\
\hline \multirow{3}{*}{$5-5{ }^{\circ} \mathrm{C}$} & $0-10$ & 0.91 & 8.8 & 26.1 & -0.7 & -25.7 \\
& $10-20$ & 0.79 & 11.4 & 25.3 & 0.4 & -23.6 \\
& $20-30$ & 0.65 & 17.3 & 25.5 & -3.6 & -27.0 \\
& $30-40$ & 0.91 & 7.4 & 16.5 & -4.0 & -21.0 \\
\hline
\end{tabular}

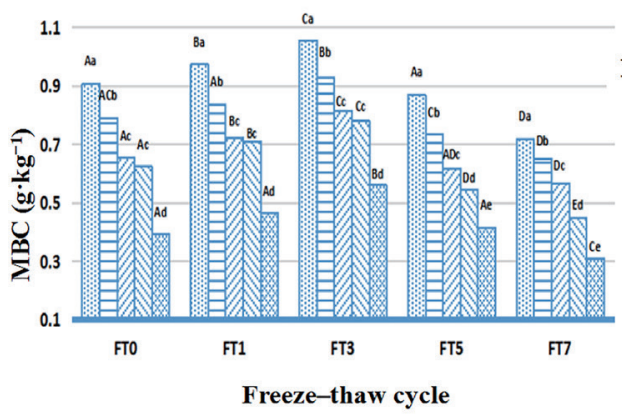

(a)

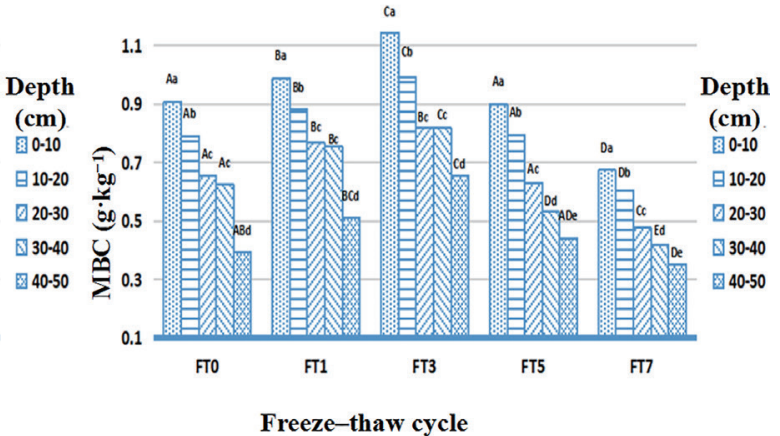

(b)

Fig. 10. (Color online) Effect of freeze-thaw cycles on soil MBC content. (a) Cycle temperatures of $-5-5{ }^{\circ} \mathrm{C}$. (b) Cycle temperatures of $-25-5{ }^{\circ} \mathrm{C}$.

an enhanced metabolic activity to survive the harsh freeze-thaw conditions, but after several cycles, most of the microorganisms died.

\subsection{WSOC content}

The freeze-thaw cycle has a significant impact on the WSOC content in soil owing to water migration during the cycle. ${ }^{(18)}$ Before the freeze-thaw cycle, the WSOC content in the soil in the depth ranges of $0-10,10-20,20-30,30-40$, and $40-50 \mathrm{~cm}$ were $0.0528,0.0494,0.0449,0.0394$, and $0.0269 \mathrm{~g} \cdot \mathrm{kg}^{-1}$, respectively. After the first freeze-thaw cycle, the WSOC content in the soils increased and then decreased significantly with more freeze-thaw cycles with the temperature ranges of $-5-5$ and $-25-5{ }^{\circ} \mathrm{C}$. After the seventh cycle, the WSOC content decreased from 73 to $88 \%$. This result is similar to the changes in MBC content, except that the WSOC content decreased after the third cycle, whereas the MBC content decreased after the fifth cycle. The enhanced metabolic activity of the microorganisms caused the increase in WSOC content, but the lack of nutrients depleted WSOC after the third cycle, leading to the drop in the activity of the microorganisms after the fifth cycles and the decrease in MBC content (Table 7, Fig. 11). 
Table 7

Changes in WSOC content in soil samples with depth and number of freeze-thaw cycles.

\begin{tabular}{lcccccc}
\hline \multirow{2}{*}{ Temperature } & $\begin{array}{c}\text { Depth } \\
(\mathrm{cm})\end{array}$ & $\begin{array}{c}\text { FT0 } \\
\text { WSOC }\left(\mathrm{g} \cdot \mathrm{kg}^{-1}\right)\end{array}$ & \multicolumn{3}{c}{ Changes in WSOC from FT0 (\%) } \\
\cline { 3 - 6 } & $0-10$ & 0.0528 & 5.9 & -63.7 & -81.3 & -73.4 \\
$-5-5{ }^{\circ} \mathrm{C}$ & $10-20$ & 0.0494 & 5.9 & -64.9 & -82.3 & -75.5 \\
& $20-30$ & 0.0449 & 8.3 & -63.5 & -83.4 & -77.9 \\
& $30-40$ & 0.0394 & 13.9 & -66.1 & -88.5 & -85.3 \\
& $40-50$ & 0.0269 & 17.8 & -55.0 & -89.6 & -81.7 \\
\hline \multirow{3}{*}{$-25-5{ }^{\circ} \mathrm{C}$} & $0-10$ & 0.0528 & 28.1 & -65.3 & -78.8 & -83.2 \\
& $10-20$ & 0.0494 & 16.1 & -60.9 & -80.0 & -84.0 \\
& $20-30$ & 0.0449 & 1.9 & -57.0 & -79.2 & -87.9 \\
& $30-40$ & 0.0394 & 0.1 & -62.3 & -79.9 & -87.5 \\
& $40-50$ & 0.0269 & 11.0 & -50.8 & -72.2 & -81.9 \\
\hline
\end{tabular}

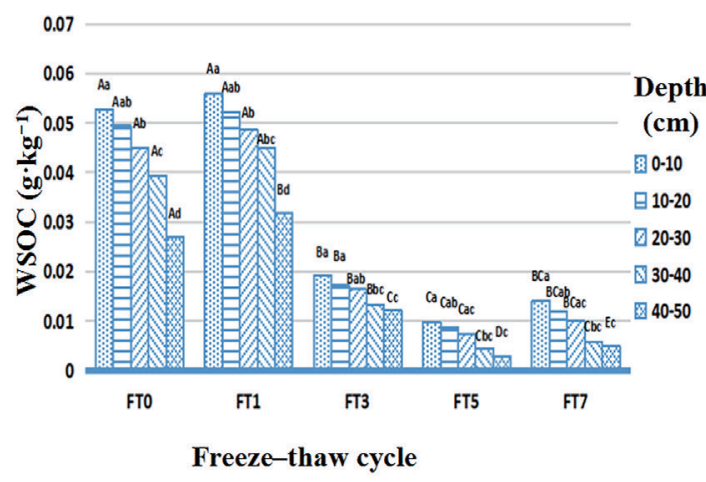

(a)

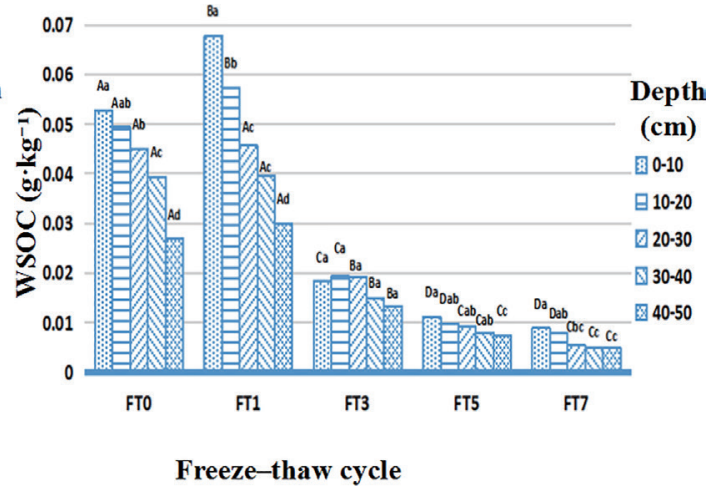

(b)

Fig. 11. (Color online) Effect of freeze-thaw cycles on soil WSOC content. (a) Cycle temperatures of $-5-5{ }^{\circ} \mathrm{C}$. (b) Cycle temperatures of $-25-5^{\circ} \mathrm{C}$.

\subsection{Correlation between SOC content and physical and chemical properties}

The correlation between physical and chemical properties and carbon contents with freezethaw cycles was analyzed, and the results are shown in Table 8. Water content was significantly correlated with bulk density, $\mathrm{pH}$, and SOC, ROOC, MBC and WSOC contents throughout the cycles $(P<0.05)$. This indicates that the water content is an important factor affecting those parameters in the soil. During the cycles, the porosity of soil affects the bulk density of soil, as well as the water holding rate and organic carbon storage capacity. We also found that with the temperature range of $-5-5^{\circ} \mathrm{C}$, the SOC content showed significant correlations with the ROOC, $\mathrm{MBC}$, and WSOC contents. However, with the temperature range of $-25-5{ }^{\circ} \mathrm{C}$, the $\mathrm{SOC}$, ROOC, MBC, and WSOC contents showed significant correlations after only the first cycle. This indicates that the carbon components in the soil are mainly controlled by the active carbon components. 
Table 8

Correlation of SOC and active components with physical and chemical properties with freeze-thaw cycles.

\begin{tabular}{|c|c|c|c|c|c|c|c|c|c|c|c|c|c|c|c|}
\hline \multirow{3}{*}{$\begin{array}{l}\text { Freeze- } \\
\text { thaw } \\
\text { cycle }\end{array}$} & \multirow{3}{*}{ Index } & \multicolumn{14}{|c|}{ Freeze-thaw temperature } \\
\hline & & \multicolumn{7}{|c|}{$-5-5{ }^{\circ} \mathrm{C}$} & \multicolumn{7}{|c|}{$-25-5{ }^{\circ} \mathrm{C}$} \\
\hline & & $\mathrm{pH}$ & $\begin{array}{l}\text { Water } \\
\text { content }\end{array}$ & $\begin{array}{c}\text { Bulk } \\
\text { density }\end{array}$ & SOC & ROOC & WSOC & $\mathrm{MBC}$ & $\mathrm{pH}$ & $\begin{array}{c}\text { Water } \\
\text { content }\end{array}$ & $\begin{array}{c}\text { Bulk } \\
\text { density }\end{array}$ & SOC & $\mathrm{ROOC}$ & WSOC & $\mathrm{MBC}$ \\
\hline \multirow{7}{*}{ FT0 } & $\mathrm{D}$ & $-.798^{* *}$ & $.967^{* *}$ & $-.894^{* *}$ & $-.923^{* *}$ & $-.975^{* *}$ & $-.938^{* *}$ & $-.957^{* *}$ & $-.798^{* *}$ & $.967^{* *}$ & $-.894^{* *}$ & $-.923^{* *}$ & $-.975^{* *}$ & $-.938^{* *}$ & $-.957^{* *}$ \\
\hline & $\mathrm{pH}$ & 1 & $-.867^{* *}$ & 0.508 & $.902^{* *}$ & $.890^{* *}$ & $.642^{* *}$ & $.744^{* *}$ & 1 & $-.867^{* *}$ & 0.508 & $.902^{* *}$ & $.890^{* *}$ & $.642^{* *}$ & $.744^{* *}$ \\
\hline & WC & & 1 & $-.783^{* *}$ & $-.921^{* *}$ & $-.979^{* *}$ & $-.840^{* *}$ & $-.890^{* *}$ & & 1 & $-.783^{* *}$ & $-.921^{* *}$ & $-.979^{* *}$ & $-.840^{* *}$ & $-.890^{* *}$ \\
\hline & $\mathrm{BD}$ & & & 1 & $.695^{* *}$ & $.783^{* *}$ & $.922^{* *}$ & $.851^{* *}$ & & & 1 & $.695^{* *}$ & $.783^{* *}$ & $.922^{* *}$ & $.851^{* *}$ \\
\hline & SOC & & & & 1 & $.964^{* *}$ & $.825^{* *}$ & $.911^{* *}$ & & & & 1 & $.964^{* *}$ & $.825^{* *}$ & $.911^{* *}$ \\
\hline & ROOC & & & & & 1 & $.872^{* *}$ & $.935^{* *}$ & & & & & 1 & $.872^{* *}$ & $.935^{* *}$ \\
\hline & WSOC & & & & & & 1 & $.955^{* *}$ & & & & & & 1 & $.955^{* *}$ \\
\hline \multirow{7}{*}{ FT1 } & $\mathrm{D}$ & $-.820^{* *}$ & $-.886^{* *}$ & $-.897^{* *}$ & $-.949^{* *}$ & $-.955^{* *}$ & $-.904^{* *}$ & $-.952^{* *}$ & $-.899^{* *}$ & $-.886^{* *}$ & $-.897^{* *}$ & $-.942^{* *}$ & $-.917^{* *}$ & $-.973^{* *}$ & $-.946^{* *}$ \\
\hline & $\mathrm{pH}$ & 1 & 0.488 & $.539 *$ & $.892^{* *}$ & $.805^{* *}$ & $.647^{* *}$ & $.783^{* *}$ & 1 & $.598^{*}$ & $.627 *$ & $.961^{* *}$ & $.889^{* *}$ & $.904^{* *}$ & $.819^{* *}$ \\
\hline & $\mathrm{WC}$ & & 1 & $.994^{* *}$ & $.769^{* *}$ & $.821^{* *}$ & $.882^{* *}$ & $.832^{* *}$ & & 1 & $.994^{* *}$ & $.706^{* *}$ & $.720^{* *}$ & $.826^{* *}$ & $.846^{* *}$ \\
\hline & BD & & & 1 & $.803^{* *}$ & $.837^{* *}$ & $.891^{* *}$ & $.847^{* *}$ & & & 1 & $.738^{* *}$ & $.739^{* *}$ & $.836^{* *}$ & $.857^{* *}$ \\
\hline & SOC & & & & 1 & $.952^{* *}$ & $.839^{* *}$ & $.934^{* *}$ & & & & 1 & $.938^{* *}$ & $.936^{* *}$ & $.912^{* *}$ \\
\hline & ROOC & & & & & 1 & $.898^{* *}$ & $.971^{* *}$ & & & & & 1 & $.912^{* *}$ & $.906^{* *}$ \\
\hline & WSOC & & & & & & 1 & $.910^{* *}$ & & & & & & 1 & $.930^{* *}$ \\
\hline \multirow{7}{*}{ FT3 } & $\mathrm{D}$ & $-.835^{* *}$ & $-.979^{* *}$ & $-.834^{* *}$ & $-.911^{* *}$ & $-.905^{* *}$ & $-.872^{* *}$ & $-.963^{* *}$ & $-.923^{* *}$ & $-.979^{* *}$ & $-.834^{* *}$ & $-.929^{* *}$ & $-.962^{* *}$ & -0.503 & $-.962^{* *}$ \\
\hline & $\mathrm{pH}$ & 1 & $.795^{* *}$ & 0.487 & $.874^{* *}$ & $.857^{* *}$ & $.709^{* *}$ & $.811^{* *}$ & 1 & $.863^{* *}$ & $.586^{*}$ & $.950^{* *}$ & $.974^{* *}$ & 0.34 & $.949^{* *}$ \\
\hline & WC & & 1 & $.911^{* *}$ & $.879^{* *}$ & $.893^{* *}$ & $.852^{* *}$ & $.979^{* *}$ & & 1 & $.911^{* *}$ & $.851^{* *}$ & $.937^{* *}$ & 0.508 & $.948^{* *}$ \\
\hline & $\mathrm{BD}$ & & & 1 & $.666^{* *}$ & $.717^{* *}$ & $.736^{* *}$ & $.870^{* *}$ & & & 1 & $.596^{*}$ & $.716^{* *}$ & $.542 *$ & $.771^{* *}$ \\
\hline & SOC & & & & 1 & $.840^{* *}$ & $.741^{* *}$ & $.890^{* *}$ & & & & 1 & $.934^{* *}$ & 0.366 & $.896^{* *}$ \\
\hline & ROOC & & & & & 1 & $.809^{* *}$ & $.872^{* *}$ & & & & & 1 & 0.376 & $.971^{* *}$ \\
\hline & WSOC & & & & & & 1 & $.848^{* *}$ & & & & & & 1 & 0.329 \\
\hline \multirow{7}{*}{ FT5 } & $\mathrm{D}$ & $-.931^{* *}$ & $-.990^{* *}$ & $-.819^{* *}$ & $-.938^{* *}$ & $-.937^{* *}$ & $-.756^{* *}$ & $-.983^{* *}$ & $-.936^{* *}$ & $-.990^{* *}$ & $-.819^{* *}$ & $-.921^{* *}$ & $-.965^{* *}$ & $-.631^{*}$ & $-.983^{* *}$ \\
\hline & $\mathrm{pH}$ & 1 & $.916^{* *}$ & $.649^{* *}$ & $.950^{* *}$ & $.895^{* *}$ & $.667^{* *}$ & $.939^{* *}$ & 1 & $.924^{* *}$ & $.670^{* *}$ & $.925^{* *}$ & $.922^{* *}$ & $.611^{*}$ & $.920^{* *}$ \\
\hline & $\mathrm{WC}$ & & 1 & $.772^{* *}$ & $.908^{* *}$ & $.926^{* *}$ & $.757^{* *}$ & $.963^{* *}$ & & 1 & $.772^{* *}$ & $.890^{* *}$ & $.934^{* *}$ & $.636^{*}$ & $.976^{* *}$ \\
\hline & BD & & & 1 & $.782^{* *}$ & $.766^{* *}$ & $.659^{* *}$ & $.800^{* *}$ & & & 1 & $.682^{* *}$ & $.746^{* *}$ & 0.487 & $.759^{* *}$ \\
\hline & SOC & & & & 1 & $.906^{* *}$ & $.693^{* *}$ & $.962^{* *}$ & & & & 1 & $.947^{* *}$ & 0.491 & $.920^{* *}$ \\
\hline & ROOC & & & & & 1 & $.696^{* *}$ & $.950^{* *}$ & & & & & 1 & $.609 *$ & $.965^{* *}$ \\
\hline & WSOC & & & & & & 1 & $.733^{* *}$ & & & & & & 1 & $.635^{*}$ \\
\hline \multirow{7}{*}{ FT7 } & $\mathrm{D}$ & $-.949^{* *}$ & $-.981^{* *}$ & $-.825^{* *}$ & $-.934^{* *}$ & $-.894^{* *}$ & $-.821^{* *}$ & $-.979^{* *}$ & $-.949^{* *}$ & $-.981^{* *}$ & $-.825^{* *}$ & $-.772^{* *}$ & $-.953^{* *}$ & $-.772^{* *}$ & $-.964^{* *}$ \\
\hline & $\mathrm{pH}$ & 1 & $.951^{* *}$ & $.666^{* *}$ & $.928^{* *}$ & $.854^{* *}$ & $.776^{* *}$ & $.893^{* *}$ & $\begin{array}{l}1 \\
\end{array}$ & $.951^{* *}$ & $.666^{* *}$ & $.798^{* *}$ & $.950^{* *}$ & $.760^{* *}$ & $.917^{* *}$ \\
\hline & WC & & 1 & $.739^{* *}$ & $.876^{* *}$ & $.854^{* *}$ & $.832^{* *}$ & $.950^{* *}$ & & 1 & $.739^{* *}$ & $.692^{* *}$ & $.903^{* *}$ & $.774^{* *}$ & $.945^{* *}$ \\
\hline & $\mathrm{BD}$ & & & 1 & $.796^{* *}$ & $.813^{* *}$ & $.650^{* *}$ & $.883^{* *}$ & & & 1 & $.649^{* *}$ & $.792^{* *}$ & 0.492 & $.751^{* *}$ \\
\hline & $\overline{\mathrm{SOC}}$ & & & & 1 & $.891^{* *}$ & $.747^{* *}$ & $.920^{* *}$ & & & & 1 & $.894^{* *}$ & 0.449 & $.754^{* *}$ \\
\hline & ROOC & & & & & 1 & $.693^{* *}$ & $.899^{* *}$ & & & & & 1 & $.716^{* *}$ & $.924^{* *}$ \\
\hline & WSOC & & & & & & 1 & $.785^{* *}$ & & & & & & 1 & $.802^{* *}$ \\
\hline
\end{tabular}

Note: (1) ${ }^{*}$ means $P<0.05 ;{ }^{* *}$ means $P<0.01$. (2) D: depth, WC: water content, and BD: bulk density.

\section{Discussion}

\subsection{Effects of freeze-thaw conditions on physicochemical properties of soil in saline- wetland}

In this study, the effects of freeze-thaw temperature and the number of cycles on the physical and chemical properties of saline-wetland soil were investigated. The freeze-thaw process generally increased the water content and bulk density of the soil. An increased water content was also observed in the previous research. ${ }^{(19)}$ Changes in water content during the 
freeze-thaw cycle affect the soil bulk density, which decreases after the cycle as water in the capillary structure is removed. In addition, the freeze-thaw process breaks down large soil aggregates, generating fine particulate matter that sticks to large particles. This makes the space between solid particles tight and narrow. ${ }^{(20)}$ The freeze-thaw process reduces soil $\mathrm{pH}$ as it promotes soil nitrification, which releases soluble organic acid. ${ }^{(21)}$ The organic acid increases the concentration of $\left[\mathrm{H}^{+}\right]$in a soil solution, causing $\mathrm{pH}$ to decrease. ${ }^{(22,23)}$

\subsection{Effects of freeze-thaw conditions on SOCs}

The freeze-thaw temperature and the number of cycles did not significantly affect the SOC content in the soil of the study area because the soil carbon pool in the study area was relatively stable. The stable carbon pool comprises the major portion of total organic carbon in the soil. Thus, a short-term temperature change would not cause any large change in SOC content. ${ }^{(24)}$ However, the contents of active carbon, such as ROOC, MBC and WSOC, were significantly affected by the number of freeze-thaw cycles. They showed a tendency to increase after the first cycle and then decreased with more cycles. The decomposition of soil organic matter is affected by temperature and humidity changes. ${ }^{(25)}$ Repeated freeze-thaw cycles reduce the decomposition ability of the soil organic matter, which causes active carbon to accumulate in the carbon pool of the soil in a short period of time. ROOC is a relatively sensitive indicator among the various types of active carbon, and its content increases during the freeze-thaw cycle. ${ }^{(26)}$

The freeze-thaw process changes the stability of soil aggregates and its structure, and the soil aggregates break up into smaller ones. This enables organic matter of small molecular size to be released. This increases the mineralization of the organic matter in soil and promotes nitrification, which causes the amount of WSOC to increase. ${ }^{(27,28)}$ This WSOC is decomposed by microbial activity, so its amount decreases gradually. The freeze-thaw temperature has a distinct effect on soil microbial activity. ${ }^{(29)}$ When soil microbes are frozen, they become dehydrated and undergo bacterial decomposition, releasing amino acids and sugars. At a high temperature, these products are utilized by other microorganisms, increasing the soil microbial biomass. ${ }^{(30)}$ However, the repetition of freeze-thaw cycles allows microorganisms to gradually adapt to the environment, so MBC increases first. However, since soil WSOC and MBC account for only a small proportion of total soil carbon, the number of freeze-thaw cycles has a significant effect on the soil active organic carbon content but a small effect on the total SOC content.

\subsection{Comparison with previous studies}

The soil carbon cycle during the freeze-thaw process has always been a concern. How to accurately control the freeze-thaw temperature is the key point of studying the freeze-thaw cycle. As a result, the conclusions of different studies cannot be unified or may even contradict each other owing to differences in experimental conditions. ${ }^{(31)}$ Therefore, research on the freeze-thaw mechanism of soil under accurately monitored conditions will be a key point in the 
Table 9

Comparison with other freeze-thaw studies.

\begin{tabular}{lcccc}
\hline & $\begin{array}{c}\text { Freeze-thaw of } \\
\text { saline-wetland }\end{array}$ & $\begin{array}{c}\text { Effects of freeze-thaw } \\
\text { on SOC, WSOC, ROOC, } \\
\text { and MBC }\end{array}$ & $\begin{array}{c}\text { Temperature sensor is used } \\
\text { to determine freeze-thaw } \\
\text { temperatures }\end{array}$ & $\begin{array}{c}\text { Field monitoring and } \\
\text { laboratory simulation }\end{array}$ \\
\hline $\begin{array}{l}\text { Other studies } \\
\text { This study }\end{array}$ & $\mathrm{N}$ & $\mathrm{N}$ & $\mathrm{N}$ & $\mathrm{N}$ \\
\hline
\end{tabular}

Table 10

Comparison with other freeze-thaw studies

\begin{tabular}{lcc}
\hline & This study & Other studies \\
\hline Research area & Saline-wetland, special soil type & Songnen Plain black soil, forest soil \\
\hline Research content & $\begin{array}{c}\text { Soil physical and chemical properties, } \\
\text { and SOC, WSOC, ROOC, and MBC contents }\end{array}$ & Single \\
\hline Research technology & $\begin{array}{c}\text { A temperature sensor is used to determine freeze-thaw } \\
\text { temperatures and all events are monitored in real time. }\end{array}$ & Laboratory simulation \\
\hline
\end{tabular}

future. In this study, a temperature sensor was used to determine the freeze-thaw temperature, and all events were monitored in real time (Table 9). Compared with previous studies, the effect of the freeze-thaw cycles on soil humus is revealed more effectively by the freeze-thaw simulation culture experiment using a temperature sensor.

Thus far, studies on the effects of the freeze-thaw process on SOC, WSOC, ROOC, and MBC have been limited to farmland and forest soils, and there is no research on the response of saline-alkali wetland soil to the freeze-thaw process. ${ }^{(32)}$ The results of this research fill this gap (Table 10).

\section{Conclusions}

We investigated the effects of different freeze-thaw temperatures and the number of freezethaw cycles on the active organic components and physicochemical properties of saline-alkali wetland soil around Chagan Lake of Songnen Plain. The water content and bulk density of the soil in the study area increased with the number of freeze-thaw cycles. The soil $\mathrm{pH}$ decreased with the increasing number of cycles. The SOC content was not significantly changed by the number of cycles. However, the contents of active carbon components such as ROOC, WSOC, and $\mathrm{MBC}$ changed with the number of cycles, showing a tendency to first increase and then decrease. Different freeze-thaw temperatures have different effects on SOC and active carbon components. With the temperatures of $-5-5{ }^{\circ} \mathrm{C}$, the correlation between SOC and active carbon components was significant $(P<0.01)$. With the temperatures of $-25-5{ }^{\circ} \mathrm{C}$, the correlation between SOC and active carbon components became significant $(P<0.01)$ only after the first freeze-thaw cycle. This implies that the freeze-thaw cycle with a wider temperature range having a lower minimum temperature has a greater effect on the carbon cycle and its pool. Thus, should global warming become more intense, bringing about greater temperature changes in the temperate zone and the permafrost region, the perturbation of the carbon pool and carbon cycle will become more severe. 


\section{Acknowledgments}

This work was partially sponsored under the auspices of Changchun University Scientific Research and Cultivation Fund (2019JBC27L40), the National Natural Science Foundation of China (Nos. 51179073 and 41471152), and the National Science Council of Taiwan under grant no. MOST 107-2221-E-507-002-MY3.

\section{References}

1 C. H. Wang, S. L. Jin, and H. X. Shi: J. Glaciol. Geocryol. 36 (2014) 1. https://doi.org/10.7522/ j.issn.1000-0240.2014.0001

2 L. F. Wang, Y. J. Cai, and H. T. Xie: Chinese J. Appl. Ecolo. 18 (2007) 10. https://doi.org/10.13287/j.10019332.2007.0393

3 L. X. Yang and J. J. Pang: Chinese. J. Soil. Sci. 35 (2004) 4. https://doi.org/10.3321/j.issn:0564-3945.2004.04.023

4 H. C. Zhao, X. Wei, Y. He, and T. Wang: J. Soil. Water. Conserv. 32 (2018) 5. https://doi.org/10.13870/j.cnki. stbcxb.2018.05.013

5 R. J. Hao, Z. P. Li, and Y. P. Che: Chinese J. Soil. Sci. 38 (2007) 6. https://doi.org/10.19336/j.cnki. trtb.2007.06.003

6 X. J. Feng, L. L. Nielsen, and M. J. Simpson: Soil. Biol. Biochem. 39 (2007) 8. https://doi.org/10.1016/ j.soilbio.2007.03.003

7 J. Yang, S. Liang, H. Zhang, J. X. Wu, and Y. Lou: Earth. Sci. 44 (2014) 2. https://doi.org/10.13278/j.cnki. jjuese.2014002209

8 N. S. Panikov and S. N. Dedysh: USA. J. Global Biol. Cycles 14 (2000) 4. https://doi.org/10.1029/1999GB900097

9 Y. Gao, X Zeng, and Q Xie: NL. Water Air Soil. 226 (2015) 7. https://10.1007/s11270-015-2479-2

10 W. M. Song, H. Wang, and G. S. Wang: USA. J. Geophys RES-Bioge. 120 (2015) 8. https://doi. org/10.1002/2015JG003043

11 Q. Liu, J. Tang, J. J. Wang, and Y. K. Qu: J. Northeast. Agric. Univ. 49 (2018) 9. https://doi.org/10.19720/j.cnki. issn.1005-9369.2018.09.006

12 L. Zhao, G. D. Cheng, and Y. J. Ding: J. Geog. Sci. 14 (2004) 4. https://doi.org/10.1007/BF02837484

13 P. Grogan, A. Michelsen, P. Ambus, and S. Jonasson: Soil. Biol. Biochemist. 36 (2004) 4. https://doi. org/10.1016/j.soilbio.2003.12.007

14 K. S. Larsen, S. Jonasson, and A. Michelsen: Appl. Soil. Ecol. 21 (2002) 3. https://doi.org/10.1016/S09291393(02)00093-8

15 L. H. Li, X. Li, M. Xu, G. Z. Wang, J. T. Yu, and P. Guo: Jiangsu. Agric. Sci. 43 (2015) 4. https://doi. org/10.15889/j.issn.1002-1302.2015.04.114

16 H. Shen, Z. H. Cao, and Z. Y. Hu: Chin. J. Ecol. 18 (1999) 3. https://doi.org/10.13292/j.1000-4890.1999.0038

17 W. G. Hu, Y. D. Zhao, P. Yan, Z. K.Wang, M. X. Chen, and Y. F. Sun: Ecol. Env. Sci. 16 (2007) 1. https://doi. org/10.16258/j.cnki.1674-5906.2007.01.036

18 F. L. Wang and J. R. Bettany: J. Environ. Qual. 22 (1993) 4. https://doi.org/10.2134/ jeq1993.00472425002200040011x

19 M. L. Wen, B. Y. Liu, X. Wei, and H. H. Liu: Chin. J. Soil. Sci. 40 (2009) 3. https://doi.org/10.19336/j.cnki. trtb.2009.03.006

20 H. O. Zhang, J. C. Xie, H. P. Nan, Q. C. Han, N. Wan, Y. Zhang, and H. Y. Wang: J. Soil. Water. Conserv. 30 (2016) 3. https://doi.org/10.13870/j.cnki.stbcxb.2016.03.047

21 M. Freppaz, B. L. Williams, A. C. Edwards, R. Scalenghe, and E. Zanini: App. Soil. Ecol. 35 (2007) 1. https:// doi.org/10.1016/j.apsoil.2006.03.012

22 Z. G. Sun and J. S. liu: Chin. J. Appl. Ecol. 18 (2006) 8. https://doi.org/10.13287/j.1001-9332.2007.0312

23 Z. R. Guo, E. C. Jin, Z. L. Nie, P. C. Jiao, and H. Dong: Advan. Water. Sci. 13 (2002) 5. https://doi. org/10.14042/j.cnki.32.1309.2002.03.006

24 M. Liu, W. T. Yu, Z. S. Jiang, and Q. Ma: Chin. J. Ecol. 2 (2006) ii. https://doi.org/10.13292/j.1000-4890.2006.0269

25 Y. Wang, L. J. Yang, C. J. Zhou, and H. X. Chu: Bullet. Water. Soil Conserv. 30 (2010) 4. https://doi. org/10.13961/j.cnki.stbctb.2010.04.027

26 G. A. Lehrsch, R. E. Sojka, D. L. Carter, and P. M. Jolley: Soil. Sci. Soc. Am. J. 55 (1990) 5. https://doi. org/10.2136/sssaj1991.03615995005500050033x

27 M. U. Kumke, H. G. Löhmannsröben, and T. Roch: J. Fluoresc. 5 (1995) 2. https://doi.org/10.1007/BF00727531 
28 W. M. Zhou, J. D. Wang, J. S. Liu, S. J. Qin, and Y. Wang: J. Ecol. Rural. Env. 24 (2008) 3. https://doi. org/10.3969/j.issn.1673-4831.2008.03.001

29 K. Hu, J. Q. Jiang, Q. L. Zhao, J. L. Duu, W. Kun, and Q. Wei: Water. Res. 45 (2011) 18. https://doi.org/10.1016/ j.watres.2011.08.064

30 A. Herrmann and E. Witter; Soil. Biol. Biochem. 34 (2002) 10. https://doi.org/10.1016/S0038-0717(02)00121-9

31 E. H. Wang, Y. S. Zhao, and X. Y. Xia: Acta Ecologica Sinica 34 (2014) 21. https://doi.org/10.5846/ stxb201307031829

32 G. N. Zhang, X. J. Lin, and Y. M. Li: Spectrosc. Spectral Anal. 38 (2018) 4. https://doi.org/10.3964/j.is sn.1000-0593(2018)04-1298-05

\section{About the Authors}

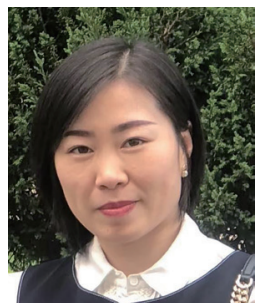

Qian Liu received her B.S. and M.S. degrees in 2006 and 2009, respectively, from Yanbian University, China. At present, she is studying in the field of environmental science at Jilin University while working as a lecturer at Changchun University. Her research interests are in SOC cycles and resource utilization. (hamiqi.365@163.com)

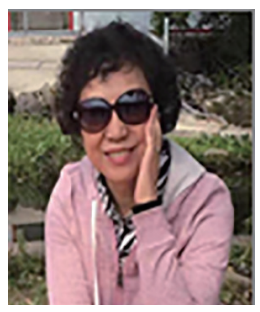

Jie Tang received her B.S. degree from Jilin University, China, in 1982 and her M.S. and Ph.D. degrees from the College of Environment and Resources, China, in 1988 and 1997, respectively. She is a professor at Jilin University, China. (tangjie0724@126.com)

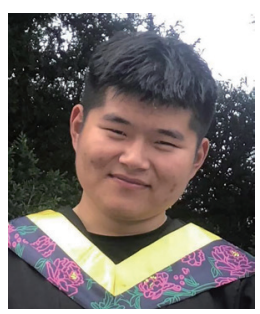

Cheng-shuai He received his B.S. degree from Changchun University, China, in 2019. At present, he is studying for a master's degree at Henan Institute of Science and Technology. His research field is environmental resources utilization. (52605501@qq.com)

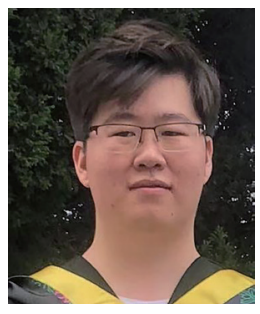

Yang Long received his B.S. degree from Changchun University, China, in 2019.

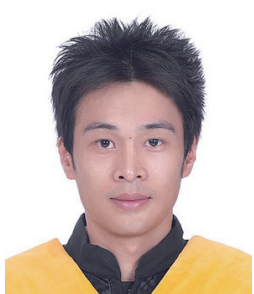

Chia-Chun Wu received his PhD degree from the Department of Computer Science and Engineering, National Chung-Hsing University, Taichung, Taiwan, in 2011. He is currently an associate professor at the Department of Industrial Engineering and Management, National Quemoy University, Kinmen County, Taiwan. His current research interests include database security, secret image sharing, mobile applications development, and digital imaging techniques. (ccwu0918@nqu.edu.tw) 